\title{
O JÚRI SIMULADO COMO RECURSO DIDÁTICO PARA PROMOVER ARGUMENTAC̣̃̃ES NA FORMAÇ̃̃O DE PROFESSORES DE FÍSICA: O PROBLEMA DO "GATO"
}

\author{
Rodrigo Drumond Vieira * \\ Viviane Florentino de Melo ** \\ José Roberto da Rocha Bernardo ***
}

RESUMO: Neste trabalho esclarecemos os papéis dos júris simulados e as suas contribuições para a produção discursiva e o aprendizado dos licenciandos em duas aulas que ocorreram em um curso de formação de professores de física. Os júris versaram sobre uma questão sociocientífica brasileira da atualidade: o problema das ligações elétricas irregulares (conhecidas como "gatos"). As análises evidenciaram como os júris simulados possibilitaram a produção de argumentos e contra-argumentos elaborados e diversificados. Discutimos como a alternância de papéis nos júris observados contribuiu para uma produção argumentativa de qualidade e para o processo de "descentralização" dos participantes, ou seja, a possibilidade de colocarem-se na perspectiva do "outro". Argumentamos que esse processo relaciona-se com a postura de scaffolding dos futuros professores, e o seu exercício durante a formação pode contribuir para que eles se tornem professores abertos ao diálogo e à argumentação em suas aulas.

Palavras-chave: Argumentação. Júri simulado. Formação de professores.

THE SIMULATED JURY AS A DIDACTIC RESOURCE TO PROMOTE ARGUMENTATION IN THE PHYSICS TEACHER EDUCATION: THE PROBLEM OF THE "CAT"

ABSTRACT: In this paper we analyze the roles of simulated juries and their contributions for discourse production and for the participants' learning in two classes of a pre-service physics teacher methods course. These classes comprised two simulated juries about a Brazilian contemporary socio-scientific question: the problem of irregular electric connections (known as "cats") in the residencies and commerce. The analyses evinced how the simulated juries afforded the construction of diverse and elaborated arguments and counterarguments. We discuss how the interchange of the participants' roles contributed to the production of quality arguments and to the participants' processes of "decentralization", that is, the possibility to put themselves in the other's perspective. We argue that such processes relate to the scaffold postures whose uses in teacher education can help the future teachers recognize the importance of the uses of more dialogue and argumentation approaches in science teaching. Keywords: Argumentation. Simulated jury. Teacher education.

\footnotetext{
* Mestre e Doutor em Educação pela Universidade Federal de Minas Gerais (UFMG). Professor do Departamento Sociedade, Educação e Conhecimento da Faculdade de Educação da Universidade Federal Fluminense (UFF). E-mail: rodrumond@gmail.com

* Mestranda em Educacãa pela Faculdade de Educação da Universidade Federal Fluminense (UFF). E-mail: melovivi2211@hotmail.com

*** Doutor em Ensino em Biociências e Saúde pelo Instituto Oswaldo Cruz - Fiocruz. Professor do Departamento Sociedade, Educação e Conhecimento e subcoordenador do Programa de PósGraduação em Educação da Faculdade de Educação da Universidade Federa Fluminense (UFF). E-mail: bernardo.jrr@gmail.com
} 


\section{INTRODUÇÃO}

As análises discursivas de interações em salas de aula estão ganhando terreno em pesquisas educacionais em todo o mundo (KELLY, 2007) e têm se firmado como um modo de compreender e repensar o discurso instrucional. Seguindo essa perspectiva, recentemente os pesquisadores têm chamado a atenção para a importância de introduzir e desenvolver mais práticas argumentativas na educação em ciências (JIMENEZ-ALEIXANDRE; ERDURAN, 2008).

Apesar das contribuições que esse programa de pesquisa trouxe para $O$ campo, relativamente pouca pesquisa tem sido investida na formação de professores de ciências, em especial, na formação de professores de física (KELLY, 2007). Assim, é necessário investir em pesquisas que visem compreender como os formadores de professores de ciências e de física, em particular, constroem conversações instrucionais com os seus estudantes nas práticas discursivas diárias de sala de aula e como essas práticas refletem nas identidades dos estudantes como futuros professores, com implicações para a sua inserção e para o seu desenvolvimento profissional.

Sob essa perspectiva, estamos interessados em compreender como formadores de professores de física introduzem a argumentação ${ }^{1}$ em seus cursos como um modo de ensino, assim como compreender como eles encorajam o desenvolvimento das habilidades argumentativas dos seus estudantes. Interessa-nos, ainda, o uso de estratégias didáticas pelos formadores que reflitam na produção de argumentações e de interações mais dialogais em suas salas de aula.

Nesse sentido, temos sugerido que o uso de júris simulados na formação de professores é uma estratégia com potencial para o estabelecimento de argumentações nesses espaços e um recurso para promover o aprendizado dos estudantes e para desenvolver suas habilidades argumentativas. Quanto a este último quesito, é fundamental que essas habilidades sejam trabalhadas na formação de professores, visando estabelecer maior coerência entre a formação e a prática docente na educação básica. A formação de professores certamente é um espaço privilegiado para a transformação de ideais e práticas e para reflexões e críticas. Trata-se, portanto, de um espaço privilegiado para a introdução, a discussão e a prática da argumentação.

De acordo com McSharry e Jones (2000), quando engajados em atividades de role-play, os estudantes devem exercer uma determinada função ou papel, ou seja, eles têm que se imaginar e se colocar no lugar de um personagem, e as suas contribuições para a atividade em desenvolvimento devem ser feitas a partir da perspectiva desse papel ou função. Nós consideramos a atividade de júri simulado como um tipo particular de role-play cuja especificidade é que as pessoas engajadas devem ser separadas em grupos a favor, contra e juízes, em uma discussão sobre um determinado tópico ou questão; ou seja, em júris simulados, há atacantes, defensores e juízes de uma questão em discussão. Nessas atividades, o professor 
pode assumir uma dessas funções ou papéis ou atuar como mediador. Ao atuar como mediador, o professor organiza e estrutura as contribuições dos grupos.

Assim, em atividades de júri simulado, os estudantes podem assumir diferentes papéis enunciativos, tais como defensor, oponente ou juiz dos argumentos produzidos - para uma discussão teórica sobre esses papéis argumentativos, veja Plantin (2005). Além disso, os estudantes podem permutar os seus papéis, experimentando posições com as quais eles não necessariamente concordam. Consideramos que a permuta de papéis nessas atividades contribui para os futuros professores exercitarem e desenvolverem competência sobre o "processo de descentralização", que se relaciona com posturas de "scaffolding" dos professores em situações de ensino e aprendizagem. Por fim, nesses júris, espera-se que os estudantes tenham ação ativa na produção de conhecimento, com impacto positivo no seu aprendizado.

A postura de "scaffolding" implica que o professor dê suporte aos argumentos dos estudantes em prol do desenvolvimento da discussão, oferecendo oportunidades para a evolução das contraposições latentes entre argumentos científicos e do cotidiano. Sob essa perspectiva, o professor pode ter que defender e oferecer justificativas para argumentos com os quais ele não necessariamente concorda, em prol do desenvolvimento da argumentação e do aumento da complexidade dos argumentos apresentados (VIEIRA, 2011; VIEIRA et al., 2012). Consideramos que o aumento da complexidade argumentativa leva a uma produção discursiva de alto valor cognitivo com implicações positivas para o aprendizado dos estudantes.

Outra recomendação da literatura é a inserção de questões sociocientíficas (QSC) na educação em ciências (SADLER, 2004; BERNARDO, 2012). Além disso, há o reconhecimento do potencial que essas questões apresentam para desencadear o desenvolvimento de argumentações em salas de aula (BERNARDO, 2012). Tendo em vista essa recomendação e a discussão desenvolvida, partimos do pressuposto de que é necessário investigar as possibilidades formativas que o júri simulado sobre QSC oferece para a formação de professores e para o estabelecimento de argumentações.

Visando reforçar os aspectos positivos relacionados à introdução de QSC por meio de discussões mediadas pelo júri simulado, o nosso objetivo neste trabalho foi analisar e caracterizar a produção discursiva de dois júris simulados desenvolvidos em um curso de formação inicial de professores de física. Os júris versaram sobre uma questão sociocientífica atual e de grande relevância no contexto brasileiro: o problema do "gato". O "gato", como é comumente chamado, corresponde a uma ligação elétrica ilegal, algo frequente no contexto brasileiro, em residências ou em estabelecimentos comercias. A discussão aconteceu em disciplina de Pesquisa e Prática de Ensino de Física, em que o professor formador utilizou júris simulados como recursos didáticos para o ensino e o aprendizado de conhecimento pedagógico e para o desenvolvimento de habilidades argumentativas dos estudantes. 


\section{REVISÃO DE LITERATURA}

Vários documentos oficiais têm alertado para a necessidade de promover o aprendizado pelos estudantes sobre os processos da ciência, incluindo-se o entendimento dos papéis da argumentação no fazer científico - Benchmarks for science literacy: Project 2061 (AAAS, 1993); National Science Education Standards (NRC, 1996); PCN (BRASIL, 1999); PCN+ (BRASIL, 2002). Nessa nova perspectiva para o ensino de ciências, os estudantes devem se engajar em atividades investigativas, semiabertas e abertas, assumindo papel ativo na delimitação e no desenvolvimento dessas atividades, o que inclui discussões baseadas em evidências, a consideração de questões sociocientíficas e o aprendizado da natureza e da história da ciência. Assim, existe uma clara tendência da educação em ciências em promover "ciência como argumento" (KUHN, 1993; ZEMBAL-SAUL, 2009).

Entretanto, professores de ciências e futuros professores ainda carecem de instrução quanto a essas novas recomendações (DUSCHL; OSBORNE, 2002). Osborne (2010) tem sugerido que a formação de professores deve ser um processo continuo em que os professores se engajem e se familiarizem com os vários aspectos das práticas científicas. Contudo, no contexto brasileiro, a inclusão de atividades baseadas em argumentação ainda não se tornou uma rotina nas salas de aula de ciências, tanto na educação básica quanto na formação de professores. Devido a essa lacuna na formação de professores e na educação básica, vários estudos foram desenvolvidos visando investigar como a argumentação pode ser inserida em sala de aula. Neste artigo, vamos nos restringir aos resultados de estudos que se relacionam diretamente com o nosso interesse de pesquisa nos júris simulados.

Simonneaux (2001) estabeleceu uma comparação entre o ensino aos estudantes via role-play e a partir do debate convencional sobre uma mesma questão: a transgênese animal. O estudo foi conduzido em duas salas de aula com estudantes do segundo ano do ensino secundário vocacional direcionado a assuntos científicos. A autora reconhece, baseada em Kolstoe (2000), que o "role-play aumenta a possibilidade de compreender o ponto de vista de outras pessoas quando você tem que se colocar no lugar dessas pessoas em uma determinada situação", afirmando que "alguns estudantes enfatizaram a dificuldade em agir sob a perspectiva de uma pessoa a respeito da qual eles não concordam” (KOLSTOE, 2000, p. 924).

Essas considerações se relacionam diretamente com os nossos pressupostos quanto às atividades de júri simulado e reforçam a necessidade de utilizar atividades de role-play e de júri simulado como modos de desenvolver os argumentos dos estudantes e dos professores, assim como desenvolver as suas habilidades argumentativas. Ainda, se os futuros professores deverão dar suporte (scaffold) para os argumentos dos alunos, então os júris simulados podem contribuir para o desenvolvimento dessa habilidade, já que eles podem experimentar posições no júri com as quais eles não necessariamente concordam. Nós consideramos que esse "processo de descentralização" pode ser necessário para os professores quando eles estiverem engajados em promover e dar suporte (scaffold) para o discurso 
argumentativo em suas salas de aula. Sob essa perspectiva, é clara a relevância do uso de atividades de júri simulado na formação de professores de ciências.

Zembaul-Saul et al. (2002) conduziram uma investigação qualitativa nos usos do software Galapagos Finches para dar suporte (scaffold) aos argumentos de futuros professores de ciências. As autoras fizeram uma análise em profundidade de dois pares de futuros professores que cursavam uma disciplina de Métodos Avançados e obtiveram vários resultados dessa investigação, entre os quais salientamos: os pares revelaram várias limitações que estão documentadas na literatura, como a falta de explicações alternativas, o não uso de diferentes tipos de evidência para dar suporte a uma afirmação e conclusões e generalizações apressadas; os pares não ofereceram justificativas - que ligam um dado a uma afirmação, isto é, uma garantia de inferência -; e, finalmente, houve a rejeição de dados anômalos, ou seja, dados que servem como contraevidência à afirmação considerada. Esses resultados confirmam que abordar o ensino de ciências por meio de ênfase na argumentação ainda é algo complexo e carregado de dificuldades.

As autoras afirmam que a falta de estratégias pedagógicas dos professores "para dar suporte aos estudantes para que eles possam se engajar em argumentações, assim como os recursos limitados para ajudar os professores na condução dessa tarefa, têm sido identificados como as maiores barreiras para a inclusão da argumentação no ensino de ciências" (ZEMBAUL-SAUL et al., 2002, p. 40). Nós reconhecemos que as atividades de júri simulado constituem um recurso alternativo para abordar tal ênfase complexa sobre a argumentação no ensino de ciências, especialmente para lidar explicitamente com alternativas e contra-alternativas com relação a um determinado assunto. Nesse sentido, é importante notar que, em atividades de júri simulado, há separações formais e explícitas das posições contra e a favor ante uma determinada questão, assim como as avaliações feitas pelos juízes sobre os argumentos apresentados, o que pode contribuir para aumentar a consciência dos estudantes sobre as perspectivas desenvolvidas.

Esta pequena revisão visou levantar razões para a introdução de júris simulados no ensino de ciências e em programas de formação de professores. Nas próximas seções, apresentamos o referencial teórico, o método e o contexto investigado. Em seguida, apresentamos análises discursivas dos dois júris simulados.

\section{REFERENCIAL TEÓRICO, METODOLOGIA E CONTEXTO INVESTIGADO}

O referencial teórico em que se baseia nossa pesquisa é o da Teoria Histórico-Cultural da Atividade (LEONT'EV, 1978), por meio da qual reconhecemos a historicidade e a mediação como aspectos constitutivos da atividade humana. A mediação implica considerar os papéis situados dos sujeitos em interação e suas relações com os recursos semióticos e materiais na produção de significados compartilhados em espaços culturais.

Para análise da construção, da comunicação e da interpretação de significados produzidos nos contextos de júris simulados, utilizamos o referencial teórico da 
sociolinguística (GUMPERZ, 1982) conjugado com a análise proposicional dos procedimentos discursivos (VIEIRA, etal., 2012; VIEIRA; KELLY,2014). Os referenciais da teoria da atividade e da sociolinguística são compatíveis e complementares, uma vez que ambos reconhecem o papel de destaque da cultura na produção, na comunicação e na interpretação de significados por indivíduos engajados em atividades sociais.

Uma integração desses referenciais foi realizada em Vieira (2011), Vieira et al. (2012) e Vieira e Kelly (2014), em que propomos uma estrutura de análise das interações discursivas em salas de aula de ciências, estrutura esta que tem sido utilizada para análise de vários contextos nesses contextos. De modo a atender as especificidades da nossa investigação sobre júris simulados, a estrutura analítica foi adaptada para investigar os júris simulados realizados em uma disciplina de Pesquisa e Prática de Ensino de Física ministrada em uma grande universidade pública do Sudeste brasileiro. Em consistência com esses referenciais teóricos, a coleta de dados seguiu orientação etnográfica, com registros em notas de campo e em áudio e vídeo.

O propósito do curso de Pesquisa e Prática de Ensino de Física é desenvolver o conhecimento pedagógico dos licenciandos por meio de uma variedade de experiências e atividades. O curso investigado teve 26 horas de contato e é obrigatório para todos os alunos da Licenciatura em Física. Neste curso, o professor formador utilizou uma série de júris simulados para promover discussões e aprendizado sobre os textos de referência da disciplina, que versavam sobre educação e sobre educação em ciências em particular. Foram objeto deste estudo júris simulados para promover discussões sobre a questão sociocientífica do "gato", ou seja, sobre ligações elétricas irregulares comumente presentes em residências brasileiras e em estabelecimentos comerciais.

Os júris sobre o "gato" ocorreram nas últimas duas aulas desse curso e tiveram grupos a favor e contra nas duas ocasiões. Esses grupos se alternaram, de modo que os licenciandos tiveram a oportunidade de defender e atacar os dois lados do debate (a favor e contra o "gato"). Assim, houve rotatividade de papéis enunciativos, o que refletiu em uma produção discursiva argumentativa diversificada e de qualidade. As discussões evoluíram com pequenas intervenções do professor formador, que atuou como mediador e organizou a distribuição dos turnos de fala.

Os júris simulados tiveram duração aproximada de 120 minutos nos dois dias, aproximadamente 60 minutos em cada dia. Os júris foram divididos por sessões: um grupo era sorteado para dar início à sessão com um argumento, que era rebatido pelo outro grupo e assim sucessivamente, até que o professor formador julgasse que o argumento tinha se saturado. Em ambos os júris, aconteceram duas sessões.

Seguindo a perspectiva analítica descrita em Vieira et al. (2012) e Vieira e Kelly (2014), foram elaborados quadros de narrativas para análise de todas as interações discursivas desenvolvidas nos dois dias de júris simulados. Nesses quadros, são elaboradas narrativas das interações discursivas, e essas narrativas são divididas em clipes de aproximadamente cinco minutos de duração. Um pequeno trecho do quadro de narrativas é mostrado no Quadro 01. Comentários do analista sobre as interações discursivas constam numa coluna separada deste quadro. Todos os nomes dos licenciandos que constam neste artigo são fictícios. 
Quadro 1: Pequeno trecho do "Quadro de Narrativas" das interações discursivas para 0 primeiro dia de júri simulado sobre o problema do "gato"

\begin{tabular}{|c|c|c|}
\hline \multicolumn{3}{|c|}{ Aula 13 - Fonte primária de informações: vídeo } \\
\hline $\begin{array}{l}N^{\circ} \text { do clipe } \\
\text { Tempo } \\
\text { início (m:s) } \\
\text { fim (m:s) } \\
\text { Duração } \\
\text { (m:s) }\end{array}$ & Narrativas das interações discursivas & $\begin{array}{c}C- \\
\text { Comentários } \\
\text { do pesquisador }\end{array}$ \\
\hline $\begin{array}{c}13 \\
04: 38 \\
08: 50\end{array}$ & 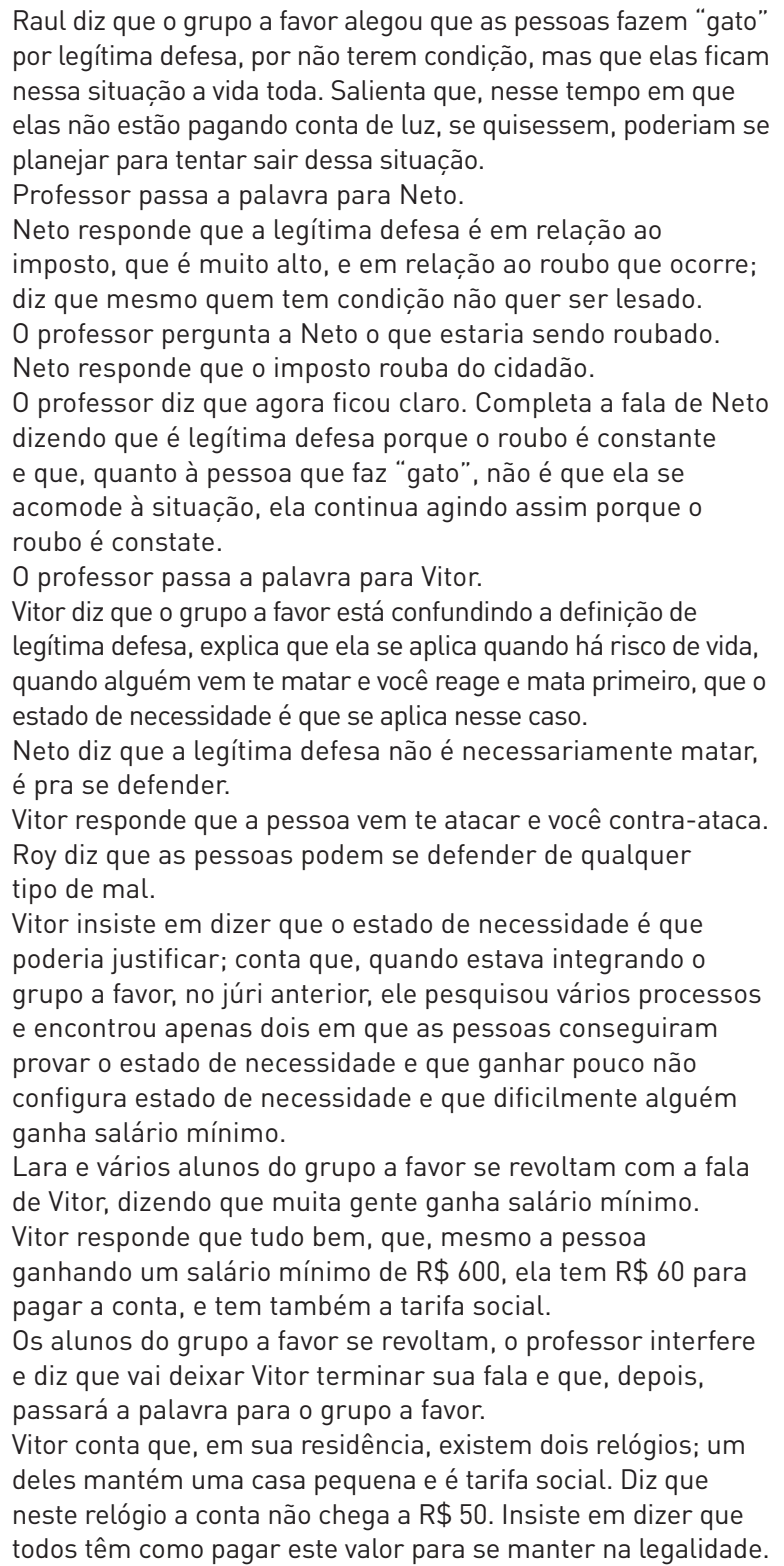 & $\begin{array}{l}\text { Raul brinca } \\
\text { dizendo que, } \\
\text { dependendo } \\
\text { do que ele } \\
\text { disser, terá } \\
\text { que mudar de } \\
\text { grupo. } \\
\text { o professor } \\
\text { questiona } \\
\text { Neto a fim de } \\
\text { esclarecer a } \\
\text { fala do aluno } \\
\text { e a completa } \\
\text { para a turma. }\end{array}$ \\
\hline
\end{tabular}




\begin{tabular}{|c|c|c|}
\hline \multicolumn{3}{|c|}{ Aula 13 - Fonte primária de informações: vídeo } \\
\hline $\begin{array}{l}N^{\circ} \text { do clipe } \\
\text { Tempo } \\
\text { início (m:s) } \\
\text { fim (m:s) } \\
\text { Duração } \\
\text { (m:s) }\end{array}$ & Narrativas das interações discursivas & $\begin{array}{c}c- \\
\text { Comentários } \\
\text { do pesquisador }\end{array}$ \\
\hline $\begin{array}{c}14 \\
08: 53\end{array}$ & $\begin{array}{l}\text { Bruno diz que são cobradas muitas taxas na conta de luz e } \\
\text { fala para Vitor que ele viu em sua pesquisa que apenas dois } \\
\text { casos foram aceitos como estado de necessidade. } \\
\text { Vitor responde que, de centenas que ele pesquisou, encontrou } \\
\text { apenas dois. } \\
\text { Bruno diz que a lei funciona pra quem está no poder, que, } \\
\text { infelizmente, em nosso país é assim. Que o "gato" é legítima } \\
\text { defesa, porque é a única defesa que a população tem. Alega } \\
\text { que é ilegal pra um setor do governo. } \\
\text { Vitor responde que, se a situação for vista dessa forma, } \\
\text { saquear o supermercado também seria legítima defesa, } \\
\text { porque está tudo caro. } \\
\text { Aluno não identificado do grupo a favor responde que ele } \\
\text { defende a legítima defesa, não o roubo. } \\
\text { O professor interfere e diz que Vitor fez uma analogia para } \\
\text { provar que, de acordo com o raciocínio do grupo a favor, pode } \\
\text { acontecer isso também. } \\
\text { Aluno não identificado responde que assalto não é legítima defesa. } \\
\text { O professor passa a palavra para Ana. } \\
\text { Ana diz que vai sair um pouco do contexto da legítima defesa. } \\
\text { O professor diz que ela pode ficar à vontade. } \\
\text { Ana diz que, quando a energia passar a ser um direito, como } \\
\text { a saúde e a educação, as pessoas terão opção de escolha e o } \\
\text { “gato" não será mais crime. } \\
\text { O professor passa a palavra para Renato. } \\
\text { Renato diz que o que Bruno falou sobre a legítima defesa } \\
\text { para o caso do "gato" é o mesmo que assaltar o mercado, já } \\
\text { que as mercadorias têm impostos altos também; alega que } \\
\text { ele está usando "dois pesos e duas medidas". Diz que roubar } \\
\text { energia também é se apossar de algo que não lhe pertence. } \\
\text { Cita o que Ana disse sobre o "gato" deixar de ser crime e a } \\
\text { energia se transformar em um direito. Questiona o grupo a } \\
\text { favor quanto à situação de, se as pessoas passarem a pagar o } \\
\text { quanto quiserem de energia, se elas não irão abusar e querer } \\
\text { pagar pouco. Insiste em dizer que o "gato" é crime e que não } \\
\text { cabe legítima defesa, que não existe "gato" legal, "gato" é } \\
\text { furto de energia. }\end{array}$ & $\begin{array}{l}\text { O professor } \\
\text { interfere na } \\
\text { discussão para } \\
\text { esclarecer a } \\
\text { intenção de } \\
\text { Vitor. }\end{array}$ \\
\hline
\end{tabular}

Ao término de cada sessão, os juízes fizeram suas avaliações individualmente e, somente no fim do júri, eles discutiram, apresentaram suas avaliações e deram o veredicto para a turma. Os resultados da análise discursiva são apresentados na próxima seção. 


\section{ANÁLISES E RESULTADOS}

A análise discursiva foi realizada a partir da integralidade dos quadros de narrativas e de transcrições de trechos selecionados deste quadro. A análise evidenciou os seguintes eixos, que influenciaram e foram produtos da atividade discursiva dos sujeitos que participaram dos júris:

1. Todos os alunos se engajaram e se prepararam para os júris de acordo com as instruções dadas pelo professor na aula anterior. Os licenciandos tiveram participação ativa na produção de conhecimento nesses júris. Os quadros abaixo documentam os principais argumentos desenvolvidos pelos grupos nos dois dias:

\section{$1^{0}$ dia de júri:}

Quadro 02: $1^{0}$ dia de júri, $1^{\text {a }}$ sessão, iniciada pelo grupo contra

\begin{tabular}{|c|c|}
\hline Grupo contra & Grupo a favor \\
\hline Quem não faz o "gato" paga por quem faz & Quem faz "gato" é por estado de necessidade \\
\hline O "gato" é crime & $\begin{array}{l}\text { As pessoas fazem "gato" por causa dos altos } \\
\text { impostos embutidos na conta }\end{array}$ \\
\hline $\begin{array}{c}\text { O "gato" é causado pela ocupação } \\
\text { desordenada do espaço }\end{array}$ & $\begin{array}{l}\text { O "gato" é a única opção em lugares aonde a } \\
\text { concessionária de energia não vai }\end{array}$ \\
\hline $\begin{array}{l}\text { As pessoas fazem "gato" por falta } \\
\text { de bom senso }\end{array}$ & $\begin{array}{l}\text { As pessoas fazem "gato" porque a crise econômica } \\
\text { e a venda de usinas deixaram a energia cara. }\end{array}$ \\
\hline O "gato" causa risco de vida & \\
\hline As pessoas que fazem "gato" agem com má-fé & \\
\hline $\begin{array}{l}\text { Quem realmente não tem condição pode } \\
\text { recorrer à justiça }\end{array}$ & \\
\hline Quem faz "gato" desperdica energia & \\
\hline
\end{tabular}

Quadro 03: $1^{0}$ dia de júri, $2^{\mathrm{a}}$ sessão, iniciada pelo grupo a favor

\begin{tabular}{|c|c|}
\hline Grupo contra & Grupo a favor \\
\hline Quem faz "gato” é corrupto & 0 "gato" ocorre porque a tarifa de energia é injusta \\
\hline $\begin{array}{l}\text { O "gato" é cultural; mesmo quem } \\
\text { não precisa faz }\end{array}$ & $\begin{array}{l}\text { O "gato" é a única opção em lugares aonde } \\
\text { a concessionária de energia não vai }\end{array}$ \\
\hline $\begin{array}{l}\text { O "gato" gera custos para a empresa de } \\
\text { energia }\end{array}$ & Quem faz "gato" é porque precisa \\
\hline $\begin{array}{l}0 \text { "gato” ocorre por falta de fiscalização das } \\
\text { empresas de energia }\end{array}$ & O “gato" é uma questão política e social \\
\hline \multirow[t]{4}{*}{0 “gato" é furto } & O "gato” é prático \\
\hline & $\begin{array}{l}\text { O "gato" acontece porque há um monopólio } \\
\text { das concessionárias de energia }\end{array}$ \\
\hline & $\begin{array}{c}0 \text { "gato" acontece porque falta estrutura } \\
\text { na sociedade }\end{array}$ \\
\hline & $\begin{array}{l}\text { Os programas assistencialistas do governo já } \\
\text { são uma espécie de "gato" }\end{array}$ \\
\hline
\end{tabular}


Observações: Nesse primeiro dia de júri, o grupo a favor limitou seu campo de defesa do "gato" apenas para os casos das pessoas que têm necessidade.

\section{$2^{\circ}$ dia de júri:}

Quadro 04: $2^{0}$ dia de júri, $1^{\text {a }}$ sessão: iniciada pelo grupo a favor

\begin{tabular}{|c|c|}
\hline Grupo contra & Grupo a favor \\
\hline 0 "gato" é crime & $\begin{array}{l}\text { As pessoas fazem "gato" por causa da alta carga } \\
\text { tributária }\end{array}$ \\
\hline $\begin{array}{l}\text { É com a carga tributária embutida na conta } \\
\text { de energia que o governo mantém serviços } \\
\text { como educação e saúde }\end{array}$ & $\begin{array}{l}\text { As pessoas fazem "gato" porque faltam } \\
\text { investimentos na rede de distribuição }\end{array}$ \\
\hline Quem faz "gato" não paga os impostos & O "gato" é uma válvula de escape da sociedade \\
\hline Não se justifica um erro com outro & $\begin{array}{c}\text { As pessoas fazem "gato" porque o sistema de } \\
\text { distribuição é adulterado }\end{array}$ \\
\hline O "gato" é uma inversão de valores & $\begin{array}{l}\text { As pessoas fazem "gato" porque a organização } \\
\text { social e política é falha }\end{array}$ \\
\hline $\begin{array}{l}\text { Para quem não pode pagar, existe a tarifa } \\
\text { de baixa renda }\end{array}$ & $\begin{array}{l}\text { A energia deveria ser um direito, pois, assim, as } \\
\text { pessoas não teriam de fazer "gato" }\end{array}$ \\
\hline 0 “gato" é cultural & $\begin{array}{l}\text { As pessoas fazem “gato" porque não há } \\
\text { investimentos satisfatórios na rede, o que } \\
\text { ocasiona apagões }\end{array}$ \\
\hline $\begin{array}{c}\text { 0 "gato" traz um alto prejuízo para as } \\
\text { empresas }\end{array}$ & $\begin{array}{l}\text { As pessoas fazem "gato" porque é feita } \\
\text { corrupção com o dinheiro dos impostos }\end{array}$ \\
\hline $\begin{array}{l}\text { O "gato" favorece a concorrência desleal no } \\
\text { comércio }\end{array}$ & O monopólio das concessionárias gera o "gato" \\
\hline \multirow[t]{5}{*}{$\begin{array}{l}\text { A tarifa de energia é alta por causa dos } \\
\text { "gatos" }\end{array}$} & Cobranças indevidas geram o "gato" \\
\hline & O "gato" é legítima defesa \\
\hline & Necessidade de reforma tributária gera o "gato" \\
\hline & $\begin{array}{c}\text { As pessoas fazem o "gato” porque o governo já } \\
\text { é corrupto }\end{array}$ \\
\hline & $\begin{array}{c}\text { O "gato" é conveniente para as empresas e para } \\
\text { o governo }\end{array}$ \\
\hline
\end{tabular}


Quadro 05: $2^{\circ}$ dia de júri, $2^{\mathrm{a}}$ sessão, iniciada pelo grupo contra:

\begin{tabular}{|c|c|}
\hline Grupo contra & Grupo a favor \\
\hline $\begin{array}{l}\text { A energia solar é uma opção ao monopólio das } \\
\text { concessionárias de energia }\end{array}$ & $\begin{array}{l}\text { Os painéis solares não funcionam à noite } \\
\text { nem quando chove }\end{array}$ \\
\hline $\begin{array}{l}\text { O dinheiro economizado com o "gato" poderia } \\
\text { ser usado para comprar os painéis solares }\end{array}$ & $\begin{array}{c}\text { O investimento necessário para a compra dos } \\
\text { painéis solares é alto, por isso as pessoas } \\
\text { fazem "gato" }\end{array}$ \\
\hline $\begin{array}{c}\text { As pessoas compram aparelhos que } \\
\text { consomem energia e, por isso, têm que pagar } \\
\text { a conta de energia }\end{array}$ & $\begin{array}{c}\text { A sociedade moderna é baseada na } \\
\text { eletricidade, que é extremamente necessária } \\
\text { para a sobrevivência }\end{array}$ \\
\hline $\begin{array}{l}\text { Ao comprar um celular, é necessário colocar } \\
\text { créditos; o mesmo vale para aparelhos que } \\
\text { consomem eletricidade }\end{array}$ & O "gato" é legítima defesa contra os impostos \\
\hline O consumismo gera o "gato" & $\begin{array}{c}\text { Antes da privatização, a energia era mais } \\
\text { barata, e, agora, as pessoas precisam } \\
\text { fazer "gato" }\end{array}$ \\
\hline $\begin{array}{c}\text { Para aqueles que não podem pagar a conta de } \\
\text { energia, existe a tarifa social }\end{array}$ & $\begin{array}{c}\text { Monopólio das empresas de energia } \\
\text { gera o "gato" }\end{array}$ \\
\hline O "gato" gera curto-circuito & Falta de assistência do governo gera o "gato" \\
\hline $\begin{array}{c}\text { O governo ajuda diminuindo o preço dos } \\
\text { produtos da linha branca, que consomem } \\
\text { menos energia }\end{array}$ & $\begin{array}{c}\text { As pessoas fazem “gato" porque } \\
\text { o salário mínimo é baixo }\end{array}$ \\
\hline \multicolumn{2}{|l|}{$\begin{array}{c}\text { O brasileiro tem o hábito de fazer instalações } \\
\text { elétricas sem segurança }\end{array}$} \\
\hline O “gato” causa incêndio & \\
\hline
\end{tabular}

Conforme evidenciado pelos quadros, a discussão se pautou em temas variados sobre a questão do "gato", ou seja, houve diversidade de argumentos nesses dois dias de júri, o que consideramos um indicador de qualidade das argumentações desenvolvidas.

2. Dois alunos mais velhos, Vitor e Lara, cada um deles integrando grupos rivais, tiveram papéis de destaque nos júris simulados, levantando argumentos fortes, que foram complementados e rebatidos durante a discussão. Acreditamos que a experiência de vida desses dois alunos os ajudou a argumentar sobre a questão sociocientífica e a liderar a produção de argumentos nos júris observados. Lara iniciou o júri nos dois dias; foi a primeira aluna de seu grupo a falar, mesmo tendo chegado um pouco atrasada no segundo dia - os alunos estavam sentados, e o professor já havia sorteado o grupo que iria iniciar o júri; nesse momento, Lara chegou à sala, sentou-se e iniciou o júri. Vitor apresentou, logo no começo do primeiro dia de júri, o argumento do estado de necessidade a favor do gato, alegando que um juiz havia absolvido uma pessoa que estava fazendo o gato por estado de necessidade, pois o juiz entendeu que o direito à vida é maior que o direito da propriedade privada. 
O trecho de transcrição abaixo evidencia o papel de destaque de Vitor quando coloca esse argumento (1º dia de júri, clipe 3 - a numeração representa os turnos de fala dos sujeitos neste clipe, assim, em cada clipe, começa-se uma nova numeração de turnos de fala; grifos nossos enfatizam trechos que dão suporte às nossas conclusões; palavras em itálico representam ênfases dos locutores; palavras entre colchetes representam comentários do analista; três asteriscos sinalizam trechos inaudíveis, ponto de interrogação entre parênteses representa aluno não identificado, três pontos entre colchetes sinalizam pausas longas, vírgulas sinalizam pausas breves):

1 - VITOR: Agora eu fiz uma pesquisa sobre a questão jurídica [...] e na verdade o, o furto de energia é previsto no artigo 155, parágrafo terceiro do código penal [...] tá, é furto, mas, existem situacões em que o crime[...] pode ser, o réu que comete 0 crime pode ser absolvido, quando ele comete o crime pelo chamado estado de necessidade, o exemplo disso é o furto famélico uma pessoa que, faminta rouba um pão sai correndo e é presa em flagrante, nesses casos o juiz pode absolver o réu, porque ele agiu no estado de necessidade, ou come ou morre[...] e há situações em que o furto de energia, ele é movido, motivado pelo estado de necessidade, eu li alguns exemplos de réus que foram absolvidos[...] por exemplo as duas irmãs que fizeram "gato" de água e luz, só que, elas viviam num estado de miséria tão grande, e tinham criança pequena em casa [...] asmática, que precisava de aparelhos, o juiz entendeu que, ali havia um estado de necessidade, suficiente para absolvê-las do crime de furto, de energia, |(?) *** | um outro caso foi de, uma pessoa que, também furtou energia, foi presa por causa da [...] desse, "gato", e foi absolvida porque tava agindo também por estado de necessidade, o "gato", ele precisava ter em casa aparelhos pra que a mãe dele sobrevivesse, então a juíza que julgou a causa ,absolveu considerando o direito à vida, ele é maior que o direito de propriedade, aí, é isso,

Esse argumento foi retomado várias vezes pelos participantes do grupo, conforme evidenciam os turnos de fala transcritos abaixo $\left(1^{\circ}\right.$ dia de júri, clipe 6 , grifos nossos):

8 - RAUL: Mas eu acho que aí, essa situação por exemplo, ${ }^{* * *}$ existem casos e casos, nesse ponto, eh, eu acho que, eu creio que é a empresa que tinha que fiscalizar isso e levar o caso ah, a justiça mesmo e tal, e a justiça julgar,_o que a gente tá defendendo, aqui, é o "gato" quando é praticado por pessoas que realmente não tem condição, entendeu?, pessoas que necessitam, esses outros casos que foram exemplificados aí pelo grupo, ah contra, eh, são casos também que se, encaixam no aspecto, geral de "gato", de furto de energia, mas são casos que quando, é levado à júri, ele é punido entendeu?, eu creio que o caso que a gente tá levantando aqui é esse de, a favor do "gato", quando ele é, feito por essas pessoas que realmente não têm condições entendeu?,

9 - LARA: Como você justifica assim | (?):***| só um minutinho desculpa, é a pessoa assim, você encontra pessoas assim, que chega até a gente assim, assim ah você quer fazer um "gato"? eu faço um "gato" pra você, pessoa que sabe fazer, eh, 
é formado tem instrução pra fazer aquilo lá, faço que a, que a companhia não vai saber nunca, que você fez, vou fazer, lá, vou botar aquelas coisas lá ***, mirabolante lá, pronto, você liga lá de noite no ar condicionado, desliga, eu não sou pobre, não sou carente num sou nada, vou usufruir da mesma maneira que o outro que tá lá, e aí?,

10 - RAUL: O erro então tá na, na, é o que eu tô falando, o erro tá na companhia então, porque a companhia ela tem que ter esse controle, ela tem que verificar, então tem até o caso do, das novas tecnologias que são esses, eu até ressaltei aqui, que são esses novos relógios digitais e tal, mas que na verdade, $\mid$ LARA: *** $\mid$ o pessoal burla, ele não tem, a concessionária não tem controle, entendeu?, a verdade é essa entendeu?, mas o fato que eu to, eu juntamente com o grupo aqui a gente tá defendendo, é a questão do "gato", feito por pessoas que realmente precisam daquilo, que não têm condições,

No primeiro dia de júri, o grupo a favor baseou quase todos os seus argumentos em torno do argumento principal levantado por Vitor: o estado de necessidade em defesa do "gato".

A licencianda Lara teve papel de destaque em desencadear a discussão do grupo a favor do "gato" no segundo dia de discussão. Ela levantou a questão da alta carga tributária no país, que tornaria "justificável" o "gato" nessas circunstâncias. O trecho de transcrição a seguir mostra como ela articulou esse argumento ( $2^{\circ}$ dia de júri, clipe 2 , grifos nossos):

16 - PROFESSOR: Elejam, deixa eu dar uma dica pra vocês, elejam uma questão que vai puxar pro lado de vocês, que vocês acham que eles vão ter o argumento mais enfraquecido, acho que a questão é essa,

17 - ANA: É que a gente não teve tempo de se reunir, então assim cada um fez uma coisa assim*** |LARA: Pois é,|

18 - LARA: Não sei se vocês pensaram, do jeito que eu pensei assim mas, | (?): pode falar, |*** eh [...] em relação à carga tributária, na conta né, as pesquisas e tudo vem, apesar de ter os problemas dos “gatos', contribuírem pro aumento da conta, ${ }^{* * *}$ né, as perdas de energia que tem desde que sai de lá até chegar em casa, tem um mapa de pizza na conta lá e tudo, o que acarreta maior, gasto mesmo nas contas, seria, o alto, custo dos tributos né?,, em relação, à questão dos apagões que houveram em 2001 [...] 2001, 2002,

19 - PROFESSOR: É foi nessa época,

20 - LARA: Foi nessa época né?, e que, foi levantada a questão de dez anos sem investimento, né?, na distribuição né, de energia e tudo, ${ }^{* * *}$ e dá é que, em virtude disso tudo, desse país que a gente vive aí, acaba as pessoas, eh, se prevalecendo ainda desse meio ilícito, porque o que antes era uma coisa voltada pras populações carentes por falta das, iniciativas de políticas governamentais, que atenda essa população carente né, hoje em dia a maioria dos "gatos" é feito mesmo pelas pessoas que têm condições de pagar!, e essas pessoas mais esclarecidas, que arcam com as despesas do, dos impostos, que tão aí pagando, a gente acorda de 
manhã cedo, tá pagando impostos, vai dormir de noite, você tá pagando imposto, tudo desse jeito, e daí que, uma alternativa né, é, a pessoa acaba[...] tirando, é, uma inversão de valores, por assim dizer né, e acaba optando pela, sonegação mesmo de, pelo "gato", porque o "gato", não é mais aquele "gato" que vai lá e puxa um fiozinho né, as pessoas já têm o seu relógio medidor tem tudo né, e o "gato" virou tigre, [risos]é bem feito uma coisa estruturada né, não estamos falando mais das pessoas que, é, leigas assim, por assim dizer, são pessoas mais instruídas [...] bom agora é com vocês aí,

Ainda no segundo dia de júri, Lara também levantou a questão do subsídio que era dado antigamente pelo governo, que tornava menos oneroso o custo da energia elétrica para a população. Assim, sob a perspectiva de ausência de subsídio, o "gato" seria justificável. O trecho de transcrição a seguir mostra como ela articulou esse argumento e como ele se desdobrou em uma discussão sobre o tipo de apoio que o governo dá à população para incentivar a redução dos gastos com energia, apoio que acaba sendo também criticado pelos licenciandos ( $2^{\circ}$ dia de júri, clipe 16$)$ :

1 - LARA: Bom, eh Furnas faz [...] eh [...] | (?) produz| produz energia, né, o governo vai subsidia, não subsidia mais né, o problema é esse né?, não tem mais subsídio do governo a gente que tem que pagar a mesmo né, por isso que essas energias antigamente era mais barata, porque havia o subsídio do governo e hoje em dia não há mais isso, aí que se, quando se tirou isso, havia a história do "gato", das populações carentes, que tavam lá, e tudo mais, que era o "gato" que vinha do muro e tal do poste, e jogava lá não passava nem *, porque não tinha nem relógio né, as pessoas não tinham relógio nem medidor não tinha nada, depois que venderam ah, as concessionárias chegaram que botaram ordem nessa bagunça, porque isso era uma bagunça danada, num tinha, nem relógio nem os medidores por aí, aí vieram com a história de trocar e botar chip todo mundo, pra tentar controlar pra ter maior controle dos gastos e tudo saber o que sai o que tá entrando nas casas, pra ter isso tudo aí, e mesmo assim eles ainda não dão conta, de que, eh esse "gato" hoje em dia, tá sendo feito, não mais somente pelas pessoas que tavam lá nas comunidades nem nada, os "gatos" tão sendo feitos de dentro, dos relógios pra dentro de casa, passa lá no relógio, e a pessoa, continua usando lá, suas coisinhas dentro de casa lá, porque paga os impostos paga tudo, eh quando ele diz o negócio da legítima defesa, é justamente porque, porque você se sente subtraído, já de todas essas cargas, de todas essas coisas que tão acontecendo aí fora, então por isso, não é que o "gato" seja legal o "gato" é crime, continua sendo crime, a gente sabe |JOSÉ: Ela falou que é crime| José olha para o professor e aponta para a Lara alegando que ela está sendo contra o "gato" em sua fala] que é crime, a gente sabe que o "gato" é crime, |PROFESSOR: Não o argumento dela tá consistente|

Até aqui, o argumento de Lara se baseia na falta de subsídio e na alta carga de impostos. O professor, mesmo com o aviso do licenciando José sobre Lara ter dito que "gato" seria crime, deixou o argumento fluir. Lara avança o argumento reforçando que o "gato" é crime - mesmo sendo do grupo a favor, apesar dessa 


\section{afirmação, o seu argumento como um todo justifica motivos para se ter ou fazer "gato" (continuação do mesmo turno de fala):}

a gente sabe que o "gato" é crime, que o "gato" é crime é crime, mas é crime se as pessoas continuam usando desses artifícios de maneira ilícita aí?, é por quê?, porque falta, eh, maior conscientização, tanto por parte da, da população, porque falta estrutura do governo de dá assistência as pessoas, se não puder cortar o mal pela raiz porque já tá difundida a ideia, de que, de que as pessoas já têm os seus "gatos" lá, é como usucapião, entendeu, [Lara ri de sua própria fala] já tem lá, já faz lá há tanto tempo que o "gato" já é seu, já se apropriou dele, mas tem que disseminar por quê?, porque tem que instruir pras pessoas não fazerem mais, tá, mas as pessoas não vão fazer por quê?, porque vão ter, uma maneira mais justa e adequada de tá pagando suas contas dentro da sua comunidade, porque senão o governo faz lá, campanha eh, eh, de, de, na, nas coisas de branca, como é que é?, fogão geladeira tudo pras pessoas comparem, corta ICM corta tudo lá, pra incentivar a compra desses produtos novos, que é barateado, porque as pessoas têm um eletrodoméstico lá, do tempo do ronca lá, | JOSÉ: ${ }^{* * *} \mid$ do tempo do ronca, do tempo do ronca dentro da sua casa, que consome um tantão de energia, uma máquina de lavar lá do, do tempo da White house lá, que consome um horror de energia, tem uma geladeira horrível, quer dizer, eu já vi campanha aí que foi feito, que eles tavam substituindo a, a linha branca aí, as geladeiras, pegando numa comunidade aí, o governo deu lá, foi lá, a concessionária de energia foi lá e substituiu esses, porque eles têm mecanismos, têm como tá fazendo essas coisas, mas, eh, eh, cultural, é tudo isso aí, enquanto não tiver uma, coisa mais, eh, do governo, com relação a isso tudo, o "gato" vai existir não tem como, como tirar ele,*** ninguém mais vai fazer “"'gato"”', não tem como ela falou o "gato" eh, legal [Lara se refere ao argumento anterior de Ana a respeito da possibilidade de existir um "gato" legal]

2 - JOSÉ: Mas essa campanha pra trocar os eletrodomésticos que você tem em casa, é pra na verdade fazer com que o seu consumo diminua, porque os aparelhos mais novos, consomem menos que os aparelhos mais antigos, eles já estão prevendo que vai ter realmente

3 - LARA: Vai haver um colapso de energia elétrica de novo aí, porque você acha o quê? não vamos ter mais apagão?,

4 - JOSÉ: Eu acho que uma forma de ajudar, de tentar colaborar, com, uma, forma de deixar mais igualitária o consumo, já não é reduzir o gasto, pelo menos de um dos *** pra você comprar mais barato, |LARA: Mas você compra mais barato| você tem o gasto com a energia, você paga, e pelo próprio aparelho em si [...] você reduzir, o gasto de um dos lados já não vai ajudar?, já que você não tem como |LARA: As lâmpadas que substituíram dentro de casa, tem medidas tudo | já não ajuda?,

5 - LARA: Tudo tem que levar eh, em conta e ver, que, que a energia não vai ter infinitamente,

6 - JOSÉ: Não tudo bem, mas o governo tem colaborado com a redução do gasto que você tem com seus aparelhos, e a manutenção dos mesmos, 
7 - PROFESSOR: Ok,

8 - DEISI: Ah eu acho que isso é mais do que obrigação né, o salário é uma vergonha eles têm que ensinar a gente a economizar, por exemplo a concessionária de energia já fornece um folhetinho até mesmo você vai no site tá escrito lá, horários de pico de seis da noite às dez da noite, evite usar tais aparelhos neste horário, eles avisam,

9 - JOSÉ: Mas isso a gente sabe que não é viável,

10 - DEISI: Ham?,

11 - JOSÉ: Isso a gente sabe que não é viável, tem gente que tem que ter um ar condicionado ligado, não é questão de luxo tem lugares que são excessivamente quentes, você tem pessoas enfermas que, realmente não podem, eh por exemplo respirar, pessoas que foram espancadas não podem transpirar, não pode cair suor, dentro dá, né?, do ferimento realmente, tem que ficar no ar condicionado não tem jeito, e aí você vai pegar o folhetinho e vai falar ah eu não posso ligar ar condicionado, no horário de pico, ah tadinho do meu filho que tá operado aqui, e aî́, não tem como,

O argumento de Lara orientou a conversa para os subsídios do governo e as ações das empresas para reduzir o consumo, como a troca de eletrodomésticos antigos por novos que consomem menos energia e os horários de pico de consumo, que devem ser evitados. Esses argumentos emergiram dessa conversa, mas foram igualmente alvo de críticas, conforme o turno final de José: "Isso a gente sabe que não é viável”, referindo-se às pessoas que são instruídas pela empresa de energia a evitar o uso de certos aparelhos em horários de pico.

Esse conjunto de argumentos episódicos evidencia como Lara exerceu liderança nesse júri, ao colocar temas e argumentos que foram desenvolvidos pelos grupos pró e contra.

3. Estabelecendo uma comparação entre os dois júris (primeiro e segundo dias), pudemos notar que, no segundo júri, os alunos estavam mais seguros, o que resultou em argumentos e contra-argumentos mais diversificados e elaborados. Nossa hipótese é que, saturados os argumentos do primeiro dia, os alunos tiveram que recorrer a outros tipos de argumento, inclusive como resposta aos argumentos do primeiro dia. Assim, houve um aumento de complexidade retórica, e isso refletiu em uma produção mais elaborada no segundo dia, o que consideramos um indicador de qualidade da argumentação desenvolvida. Essa tendência pode ser averiguada pela inspeção dos argumentos apresentados no primeiro e no segundo dia de júri sobre o "gato", conforme consta nos quadros 2, 3, 4 e 5.

4. Constatou-se emergência de contraposição triádica, em que um argumento é elaborado, contraposto e novamente reelaborado. No segundo dia de júri, no clipe 14, o licenciando Bruno (do grupo a favor) usou o argumento de que o "gato" seria legítima defesa, porque a energia seria cara, devido aos altos impostos inclusos na conta. Em resposta a esse argumento, 
ainda no clipe 14, o licenciando Vitor (do grupo contra) utilizou uma analogia, afirmando que, "se essa situação for vista dessa forma, saquear um supermercado também seria legítima defesa, porque está tudo caro". O professor explicou para a turma que a contribuição do licenciando Vitor era uma analogia para mostrar que, de acordo com o raciocínio do grupo a favor, poderia acontecer também o saqueamento de supermercado. Após alguns turnos de fala, no clipe 15, o licenciando Neto retoma a analogia de Vitor e alega que, no mercado, existem várias opções de produtos mais baratos e que também existem várias opções de mercados que vendem mais barato, sendo que com a energia não há escolha. Assim, pudemos perceber como um argumento se torna mais complexo e delimitadoà medida que é reelaborado pelos licenciandos, que continuamente pensam em respostas para as contraposições construídas durante o desenvolvimento da discussão. Ou seja, a consciência das consequências do argumento levantado por Bruno não é prontamente dada, mas construída ao longo da discussão. Essa contínua (re)elaboração dos argumentos é mais um indicador da qualidade das argumentações desenvolvidas.

5. Outro ponto importante a salientar foi a apresentação de informação parcial feita por dois licenciandos. No primeiro dia de júri, quando integrava o grupo contra o "gato", a aluna Júlia contou que seu irmão, que tem uma boa condição financeira, desperdiça energia elétrica porque tem "gato" em sua residência. No segundo júri, quando compunha o grupo a favor, ela retomou a história e, desta vez, salientou que o "gato" na casa de seu irmão tinha sido oferecido e realizado por um funcionário da própria concessionária de energia, que, na ocasião, havia alegado que o sistema de distribuição em que trabalhava era todo fraudado.

O argumento contra aconteceu no primeiro dia de júri, clipe 12:

7 - PROFESSOR: Pera aí pessoal, [vários alunos falam e riem ao mesmo tempo e o professor eleva o tom de sua voz] vou dar a voz pras pessoas, só um minutinho, eu vou começar a dar a voz pras pessoas que não falaram ainda, a Júlia levantou a mão, fala aí Júlia depois eu vou passar pro Vitor, depois eu vou voltar aqui pra você, [professor aponta para uma aluna do grupo contra]

8 - JÚLIA: Essa é uma questão totalmente cultural porque o meu irmão ele ganha superbem, ele mora num bairro bom e ele tem "gato" em casa, sabe pra quê?, pra ficar o dia inteiro com o ar condicionado ligado, |LARA: Viu! | e aí?, você acha isso certo?

Ou seja, Júlia denuncia o desperdício de seu irmão e aponta que, mesmo tendo boa condição financeira, ele, ainda assim, utiliza o "gato", e isso seria devido a uma questão cultural do brasileiro de sempre querer tirar proveito.

$\mathrm{O}$ argumento a favor aconteceu no segundo dia de júri (clipe 3): 
4 - JÚLIA: Eu falei do meu irmão né?, [ela se refere ao júri anterior] [vários alunos falam ao mesmo tempo e riem] agora eu vou completar, a informação, por que o que eu falei, parte que, eu era contra né!, o que que acontece, quem ofereceu esse "gato" pra ele foi o próprio funcionário da concessionária de energia, então foi ele que foi lá, que puxou o "gato", e o próprio funcionário falou que achava um absurdo o valor que era cobrado, que era tudo adulterado mesmo,

Em sua fala, Júlia articula o fato de que, "se tudo é fraudado mesmo, então não faz diferença eu também fazer um 'gato”" ou “já que todos fazem errado, eu também posso fazer errado". O seu argumento se constitui a partir de um topos, ou seja, um lugar-comum na cultura brasileira. Assim, novamente, o seu argumento se baseia em parâmetros culturais do brasileiro.

O outro exemplo de recorte parcial foi do aluno Vitor, que, quando fez parte do grupo a favor, citou dois processos nos quais o juiz absolveu as pessoas que fizeram "gato" alegando estado de necessidade, conforme mostramos anteriormente. No júri seguinte, quando integrava o grupo contra o "gato", Vitor revelou que, em sua busca por esses processos, encontrou apenas essas duas absolvições entre centenas de casos. $\mathrm{O}$ trecho de transcrição abaixo evidencia essa mudança de perspectiva ( $2^{\circ}$ dia de júri, clipe 13 , grifos nossos):

4 - PROFESSOR: Roubo de, pera aí, só pra eu entender o que você está dizendo, roubo de quê?,

5 - NETO: ***é que o imposto rouba da gente,

6 - PROFESSOR: ah tá, agora ficou claro, entendeu, o roubo do imposto[...] | NETO: *** | então ele tá falando que é legítima defesa porque, o roubo é constante, o tempo todo né?,

7 - NETO: É independente se você tem, tem condições de pagar ou não,

8 - PROFESSOR: Então o cara não é que ele acomoda, ele tá em legítima defesa constantemente porque o roubo tá aí o tempo todo,

9 - NETO: Isso,

10 - PROFESSOR: Fala aí Vitor,

11 - VITOR: Não confunda legítima defesa, que legítima defesa é vida, alguém vem te matar e você reage e mata antes, isso é legítima defesa, estado de necessidade é que,

12 - NETO: Não necessariamente matando né, pra se defender, legítima defesa,

13 - VITOR: A pessoa vem te atacar e você vai e contra-ataca,

14 - ROY: Você pode se defender de qualquer tipo de mal, que seja cometido a você,

15 - NETO: É, não de vida,

16 - ROY: Não necessariamente vida, 
17 - VITOR: O estado de necessidade, é que poderia justificar agora, eu, quando tava no grupo a favor do "gato" eu pesquisei, centenas de ações judiciais, só dois, lograram êxito em provar que, estavam em estado de necessidade, entende, ter ou não ter renda, ganhar pouco, não justifica o "gato", salário mínimo hoje é, pouco mais de 600 reais ninguém, dificilmente alguém ganha salário mínimo [...] [vários alunos se revoltam com a afirmação de Vitor] não é possível que não possa pagar,

Consideramos que esses resultados são consequência da alternância de papéis, que refletiu na complexidade dos argumentos desenvolvidos e na seleção de informações parciais apresentadas de acordo com o papel enunciativo exercido, como foi o caso para os licenciandos Júlia e Vitor. Nesse sentido, avaliamos que as atividades de júri simulado e a alternância de papéis foram fundamentais para viabilizar argumentações de qualidade sobre uma questão sociocientífica e para promover o processo de "descentralização", que se manifestou na apresentação de informações parciais pelos licenciandos para argumentar sob a perspectiva de papéis enunciativos diferenciados, ou seja, os licenciandos tiveram a oportunidade de se colocar na perspectiva do "outro". Consideramos que o processo de descentralização relaciona-se com a postura de scaffolding dos futuros professores e que o seu exercício durante a formação pode contribuir para que eles se tornem professores abertos ao diálogo e à argumentação em suas salas de aula.

$\mathrm{Na}$ oitava aula do curso investigado, após uma atividade de júri simulado a respeito de um texto sobre os saberes docentes, os licenciandos foram solicitados a refletir em casa e a se manifestar por escrito sobre as atividades de júri até então desenvolvidas. Os licenciandos avaliaram muito positivamente as atividades de júri simulado e reconheceram que estas tiveram um papel positivo quanto à abordagem da perspectiva do “outro”. Nós também consideramos que os júris simulados tiveram um impacto positivo no aprendizado dos licenciandos e, fundamentalmente, contribuíram para o desenvolvimento da habilidade argumentativa deles em "colocar-se no lugar do outro", o que, de acordo com Simonneaux (2001, p. 924), "aumenta a possibilidade de compreender o ponto de vista de outras pessoas". Acreditamos que essa seja uma habilidade didática crucial para que os professores e os futuros professores possam promover e desenvolver argumentações em suas salas de aula.

Quanto aos dois júris simulados sobre a questão sociocientífica do "gato", os juízes acompanharam as discussões e sintetizaram suas avaliações dos argumentos apresentados. A coerência, o detalhamento e a riqueza na síntese dos argumentos foram indicadores de que os juízes acompanharam atentamente e ativamente os argumentos desenvolvidos. Devido a questões de espaço, neste artigo, não apresentaremos as sínteses dos juízes.

O professor atuou como mediador, tomando decisões importantes em prol do desenvolvimento da discussão, como a distribuição de turnos de fala, interrupções de turnos e a organização do tempo adequado para os licenciandos desenvolverem os argumentos. Este foi o caso para a fala de Lara no grupo a favor, em que, mesmo diante da afirmação de José de que ela estaria atuando contra o 
"gato", o professor permitiu que ela continuasse e articulasse o seu argumento, que era, afinal, do ponto de vista de alguém que estava defendendo o "gato" naquele momento. Assim, a atuação do professor foi fundamental para o desenvolvimento dos júris.

É importante notar também que os licenciandos haviam participado de cinco júris simulados no curso observado - que versaram sobre os textos de referência - anteriormente aos dois dias de júri sobre o "gato". Nos júris anteriores, o professor teve papel mais ativo na determinação e na organização da atividade, levantando questões e sistematizando contribuições, algo que não ocorreu nos dois últimos júris, em que esse papel foi delegado aos licenciandos, que tiveram mais liberdade no desenrolar das discussões, ou seja, os licenciandos assumiram uma postura mais autônoma na produção discursiva. Assim, o professor, de certa forma, "preparou" os licenciandos para os dois últimos júris, assumindo nestes mais a função de mediador das interações do que de participante ou questionador. Por fim, reconhecemos que os papéis argumentativos dos licenciandos, por terem sido bem-estabelecidos desde o começo de cada júri, facilitaram as avaliações dos juízes sobre os argumentos apresentados.

\section{CONSIDERAC̣ÕES FINAIS}

O grande engajamento dos estudantes e a alternância de papéis enunciativos nos dois júris sobre o "gato" refletiram em uma produção discursiva de qualidade, com implicações positivas para o seu aprendizado e para a compreensão das contradições desenvolvidas ao longo dos júris.

Consideramos importante que professores sejam instruídos no sentido de defender opiniões contrárias às suas e que essas instruções podem ocorrer catalisadas pela abordagem de questões sociocientíficas, conforme apontado em Bernardo (2012), observado o caráter eminentemente controverso que esses temas carregam.

Ao praticar a defesa de argumentos contrários à sua opinião, o professor pode oferecê-los como suporte para o desenvolvimento de argumentos embrionários ou incompletos dos estudantes, tanto do senso comum quanto científicos. Nesse sentido, o professor pode atuar como scaffolding dos argumentos construídos pelos estudantes e também no sentido de manter a dinâmica argumentativa e ajudá-los a incorporar elementos do discurso científico. Os resultados deste trabalho evidenciam que futuros professores de física que argumentam contra a própria opinião são capazes de oferecer evidências e justificativas consistentes. Nesse sentido, a formação de professores pode se orientar para o desenvolvimento de habilidades que o ensino tradicional não aborda, como o gerenciamento de argumentações.

Especificamente em atividades de júri simulado, os participantes podem assumir papéis enunciativos diferenciados, tais como defensor, oponente ou juiz dos argumentos produzidos. Além disso, nessas atividades, os participantes podem permutar os seus papéis, experimentando posições com as quais eles não 
necessariamente concordam, podendo colocar-se na perspectiva do "outro". A permuta de papéis nessas atividades pode contribuir para que eles exercitem e desenvolvam competência sobre o "processo de descentralização", o qual se relaciona com posturas de "scaffolding" e pode contribuir para o desenvolvimento de habilidades argumentativas de professores e futuros professores em situações de ensino e aprendizado de ciências. Essa alternância de papéis é uma possibilidade de pesquisa que pretendemos explorar em novos designers de júris simulados e em situações de entrevista com os sujeitos participantes. Salientamos que as atividades de júris simulados permitem, ainda, a abordagem de contraposições e refutações de forma explícita e estruturada.

Assim, concluímos este trabalho afirmando o potencial didático dos júris simulados para promover o debate de questões sociocientíficas na formação de professores de ciências. Os júris simulados são atividades que favorecem a argumentação em salas de aula, ou seja, são recursos didáticos para promover argumentações e desenvolver as habilidades argumentativas dos estudantes. Nesses júris, espera-se que os estudantes tenham participação ativa na produção de conhecimento, gerando-se impacto positivo no seu aprendizado e em suas identidades como futuros professores. Nesse sentido, concluímos este trabalho delineando questões e perspectivas de pesquisa quanto aos usos de atividades de júri simulado no ensino de ciências, tanto no âmbito nacional quanto no internacional:

- Por meio de quais dinâmicas, ações e procedimentos o professor gerencia e organiza diferentes atividades de júris simulados?

- Como outras formas de interação entre os participantes em atividades de júri simulado influenciam a produção discursiva de sala de aula e, portanto, podem refletir no aprendizado dos estudantes?

- Como atividades de júris simulados em que os estudantes defendem suas opiniões próprias contribuem para uma produção discursiva diferenciada?

- De que maneiras as atividades de júris simulados podem ser utilizadas como recursos de ensino na educação básica?

- Quais são as diferenças e as convergências entre os júris simulados baseados em conhecimento científico e físico e os júris baseados em questões sociocientíficas? Como atividades de júris simulados sobre conhecimento físico podem ser estabelecidas?

- De que formas as atividades de júri simulado e a rotatividade de papéis (atacar, defender e julgar) contribuem para os processos de "descentralização" (colocar-se na perspectiva do outro) dos futuros professores e para as suas posturas de scaffolding ao ensinarem ciências?

- Como os usos de atividades de júris simulados podem ajudar os futuros professores a desenvolver as suas habilidades argumentativas? Essa abordagem pode ter impacto na prática dos futuros professores e propiciar condições para que eles utilizem mais práticas argumentativas em suas salas de aula? 


\section{NOTA}

${ }^{1}$ Reconhecemos o papel de destaque das contradições e das refutações no estabelecimento e na manutenção de argumentações, inclusive em contextos de salas de aula. Para maiores detalhes dessa perspectiva, veja Kuhn (1993), Billig (1996) e Vieira e Nascimento (2009).

\section{REFERÊNCIAS}

AMERICAN ASSOCIATION FOR THE ADVANCEMENT OF SCIENCE (AAAS). Benchmarks for science literacy: Project 2061. New York: Oxford University Press, 1993.

BERNARDO, J. R. R. The pre-service physics teacher and the challenge of the socio-scientific issues-based approach. E-Book from THE EUROPEAN SCIENCE EDUCATION RESEARCH ASSOCIATION CONFERENCE - ESERA 2011, p. 954-960, 2012.

BILLIG, M. Arguing and thinking: A rhetorical approach to social psychology. Cambridge: Cambridge University Press, 1996.

BRASIL. Ministério da Educação. Secretaria de Educação Média e Tecnológica. Parâmetros Curriculares Nacionais: Ensino Médio. Brasília: MEC/Semtec, 1999.

. Ministério da Educação. Secretaria de Educação Média e Tecnológica. (2002). PCN+ Ensino Médio: orientações educacionais complementares aos Parâmetros Curriculares Nacionais. Ciências da Natureza, Matemática e suas Tecnologias. Brasília: MEC/Semtec, 2002.

DUSCHL, R. A.; OSBORNE, J. Supporting and promoting argumentation discourse in science education. Studies in Science Education, v.38, p. 39-72. 2002.

GUMPERZ, J. J. Discourse strategies. Cambridge: Cambridge University Press, 1982.

JIMÉNEZ-ALEIXANDRE, M. P.; ERDURAN, S. Argumentation in science education: an overview. In: . (Org.). Argumentation in science education: Recent developments and future directions. Dordrecht: Springer, 2008. p. 3-27.

KELLY, G. J. Discourse in science classrooms. In: ABELL, S.; LEDERMAN, N. (Org.). Handbook of research on Science Education. Mahwah, NJ: Lawrence Erlbaum Associates, 2007. p. 443-470.

KOLSTOE, S. D. Consensus projects: teaching science for citizenship. International Journal of Science Education, v. 22, p. 645-664. 2000.

KUHN, D. Science as argument: Implications for teaching and learning scientific thinking. Science Education, v. 77(3), p. 319-337. 1993.

LEONT'EV, A. N. Activity, consciousness, and personality. Englewood Cliffs, NJ: Prentice-Hall, 1978.

MCSHARRY, G.; JONES, S. Role-play in Science Teaching and Learning. School Science Review, v.82 (298), p. 73-82. 2000.

NATIONAL RESEARCH COUNCIL (NRC). National science education standards. Washington, DC: National Academy Press, 1996.

OSBORNE, J. Arguing to learn in science: the role of collaborative, critical discourse. Science, v. 328(5.977), p. 463-466. 2010.

PLANTIN, C. L'argumentation. Paris: Presses Universitaires de France, 2005.

SADLER, T. Informal reasoning regarding socioscientific issues: a critical review of research. Journal of Research in Science Teacbing, v.41(5), p. 513-536. 2004.

SIMONNEAUX, L. Role-play or debate to promote students' argumentation and justification on an issue in animal transgenesis. International Journal of Science Education, v. 23, p. 903-927. 2001.

VIEIRA, R. D.; NASCIMENTO, S. S. Uma proposta de critérios marcadores para identificação de situações argumentativas em salas de aula de ciências. Caderno Brasileiro de Ensino de Física, Florianópolis, v. 26(1), p. 81-102. 2009. 
VIEIRA, R. D. Discurso em salas de aula de ciências: Uma estrutura de análise baseada na teoria da atividade, sociolinguística e linguística textual. Orientadora: Silvania Sousa do Nascimento. 2011. 139 f. Tese (Doutorado em Educação) - Faculdade de Educação, Universidade Federal de Minas Gerais, 2011.

VIEIRA, R. D., et al. An activity theory-based analytic framework for the study of discourse in science classrooms. Ensaio Pesquisa em Educação em Ciências (Online), v.14(2), p.13-46. 2012.

VIEIRA, R. D.; KELLY, G. J. Multi-level discourse analysis in a physics teaching methods course from the psychological perspective of activity theory. International Journal of Science Education, v.36(16), p. 2.694-2.718. 2014.

ZEMBAL-SAUL, C. Learning to teach elementary school science as argument. Science Education, v.93, p. 687-719. 2009.

ZEMBAL-SAUL, C., et al. Scaffolding pre-service science teachers' evidence-based arguments during an investigation of natural selection. Research in Science Education, v. 32(4), p. 437-463. 2002.

Data Recebimento: 04/07/2014

Data Aprovação: 04/11/2014

Data Versão Final: 13/11/2014

\section{Contato:}

Rodrigo Drumond Vieira

Universidade Federal Fluminense, Faculdade de Educação.

Rua Professor Marcos Waldemar de Freitas Reis

São Domingos - Niterói, RJ - Brasil 
